\title{
Value of stereotactic 11-gauge vacuum-assisted breast biopsy in non-palpable suspicious calcifications: an eight-year single institution experience with 587 patients
}

\author{
Shiping $\mathrm{Li}^{\#}$, Feilin $\mathrm{Qu}^{\#}$, Yinlong Yang, Lei Wang, Juping Shen, Zhiming Shao \\ Department of Breast Surgery, Fudan University Shanghai Cancer Center, Shanghai, China \\ Contributions: (I) Conception and design: S Li, J Shen, Z Shao; (II) Administrative support: J Shen, Z Shao; (III) Provision of study materials or \\ patients: S Li, J Shen; (IV) Collection and assembly of data: S Li, F Qu, Y Yang, L Wang; (V) Data analysis and interpretation: S Li, F Qu; (VI) \\ Manuscript writing: All authors; (VII) Final approval of manuscript: All authors. \\ "These authors contributed equally to this work. \\ Correspondence to: Juping Shen. Department of Breast Surgery, Fudan University Shanghai Cancer Center, No. 270 Dong'an Road, Xuhui District, \\ Shanghai, China. Email: jupingshen@163.com.
}

Background: Vacuum-assisted breast biopsy (VABB) has been routinely recommended for stereotactic intervention in cases of isolate mammographically-detected calcifications. Herein we aimed to evaluate and compare the diagnostic consistency and accuracy of calcified and noncalcified specimens obtained from same sites of sampling on mammography-visible calcifications. In addition, we presented the biopsy procedure and retrospectively evaluated the usefulness of $\mathrm{VABB}$ as well as the complications of this technique over an eightyear experience in our centre.

Methods: This single-institution observational cohort study included 587 patients referred for stereotactic 11-gauge VABB of 594 mammographically-detected calcifications between January 2010 and December 2018. The rate of histopathological underestimation, the false negative, the diagnostic consistency and accuracy between calcified and noncalcified specimens of VABB were comprehensively evaluated based on the surveillance data and final histopathological result of the surgical specimens.

Results: In total, 594 biopsy procedures were performed in 587 patients (mean age 46 years, range, 2180 years). The average number of biopsy specimens was 14.7 (range, 9-21) per lesion. VABB pathological results revealed 471 (79.3\%) benign, 39 (6.6\%) high-risk, and $84(14.1 \%)$ malignant cases. The diagnostic inconsistency between calcified and noncalcified specimens was $14.6 \%(105 / 123)$ for high-risk and malignant lesions. Furthermore, calcified specimens exhibited higher diagnostic accuracy of malignant lesion as compared with the noncalcified specimens ( $97.7 \%$ versus $82.6 \%$, respectively). Underestimation rate for high-risk lesions and in situ carcinoma was $5.1 \%$ and $54.1 \%$, respectively, along with a false negative rate of $6.25 \%$. In addition, mild complications were reported with high patient tolerance.

Conclusions: Stereotactic $11 \mathrm{G}-\mathrm{VABB}$ might be preferred for the investigation of non-palpable mammographically-detected calcifications in terms of accuracy and safety profile. The high prevalence of diagnostic discordance between the specimens with and without calcifications revealed a higher value of calcified specimens in diagnosing high-risk and malignant calcifications.

Keywords: 11-gauge; non-palpable calcifications; stereotactic vacuum-assisted breast biopsy (stereotactic VABB); calcified and noncalcified specimens

Submitted Apr 14, 2020. Accepted for publication Sep 10, 2020.

doi: $10.21037 /$ gs-20-456

View this article at: http://dx.doi.org/10.21037/gs-20-456 


\section{Introduction}

With the widespread introduction of screening mammography, the detection of non-palpable breast lesions has increasingly identified, exclusively for calcifications patterns. In case of suspicious non-palpable abnormalities, a hook wire localization biopsy remains to be the standard option for obtaining histopathological assessment (1). However, the cosmetic outcome and morbidity associated with an open excisional biopsy have prompted more physicians to evaluate other alternative procedures, preferably in a timely, non-operative way.

Palpable and nonpalpable breast lesions are currently available to be diagnosed by different percutaneous imageguided techniques. Core needle biopsy (CNB) is the most commonly used approach for a US-visible lesion while the vacuum-assisted breast biopsy (VABB) can be performed under mammography, tomosynthesis, US, or MRI guidance. The use of VABB is crucial for findings such as microcalcifications or architectural tissue distortions on mammography or tomosynthesis as well as for suspicious contrast-enhancing lesions on MRI that cannot be found with other methods (2). Studies have shown that VABB is superior to large core breast biopsy, harvesting higher quality and larger volume of specimens which results in increased lesion retrieval, decreased cancer underestimation rates and reduced sampling error (3-5).

Additionally, use of vacuum-assisted technique towards a targeted area enables removal of larger amounts of tissue both calcifications included and not. The retrieval of suspicious calcifications has been confirmed to facilitate histopathologic diagnosis because the targeted calcifications tended to represent typical features of comedo necrosis from in situ malignancy on microscopy (6). However, the presence or absence of calcifications in the core specimens might lead to different histopathologic diagnoses, despite being collected from the same biopsied site.

The primary objective of this study was to evaluate and compare the diagnostic consistency and accuracy of specimens with or without calcifications obtained from same sites of sampling on isolate mammographically detected calcifications. In addition, we presented the biopsy procedure and retrospectively evaluated the usefulness of $\mathrm{VABB}$ in non-palpable lesions, as well as the complications of this technique over an eight-year experience in our centre. We present the following article in accordance with the STROBE reporting checklist (available at http:// dx. doi. org/10. 21037/gs-20-456).

\section{Methods}

From January 2010 to December 2018, stereotactic VABBs were performed in 642 consecutive patients with non-palpable lesions in our centre. Thirty-six patients were not eligible for inclusion because a mass lesion was synchronously delineated on ultrasound. Another 12 patients were excluded due to lack of follow-up information.

The remaining 587 patients with 594 mammographically detected calcifications were eventually included in this study (Figure 1). Before biopsy, breast calcifications were classified according to the new edition of mammographic BI-RADS (Breast Imaging Reporting and Data System) morphology descriptors published in 2013 (7).

In our study, some patients with BI-RADS 0 category lesions also underwent VABB either because of positive family history of breast cancer or patient's strong willingness. Among them, calcifications were mammographically confirmed and additional imaging examinations were provided before biopsy. Moreover, patients with poor compliance for mammography follow up were also submitted to the VABB procedure.

\section{Stereotactic vacuum-assisted biopsy procedure}

Biopsy procedures were completed by two experienced breast surgeons specialized in performing breast biopsy. All VABBs were performed under stereotactic guidance with a 11-gauge Mammotome device (Brevera ${ }^{\circledR}$ Breast Biopsy System, Hologic) on the digital prone table (Affirm ${ }^{\circledR}$ Prone Breast Biopsy System, Hologic). Detailed biopsy protocols are identical to those described elsewhere in the literature (8). The presence of calcifications was determined by using specimen radiographs after retrieval. Specimens with and without calcifications were submitted separately to pathologic examination in two different labelled formalin containers.

\section{Histopathological evaluation procedure}

Histopathological analysis of all biopsy specimens was retrospectively accomplished by two dedicated breast pathologists. The histopathological diagnosis was subdivided into 3 categories: benign, high-risk, and malignant. High-risk lesions comprised atypical ductal hyperplasia (ADH) and atypical lobular hyperplasia (ALH) while malignant lesions included ductal carcinoma in situ (DCIS), lobular carcinoma in situ (LCIS), carcinoma in situ with microinvasion (DCIS-MI), and invasive ductal 


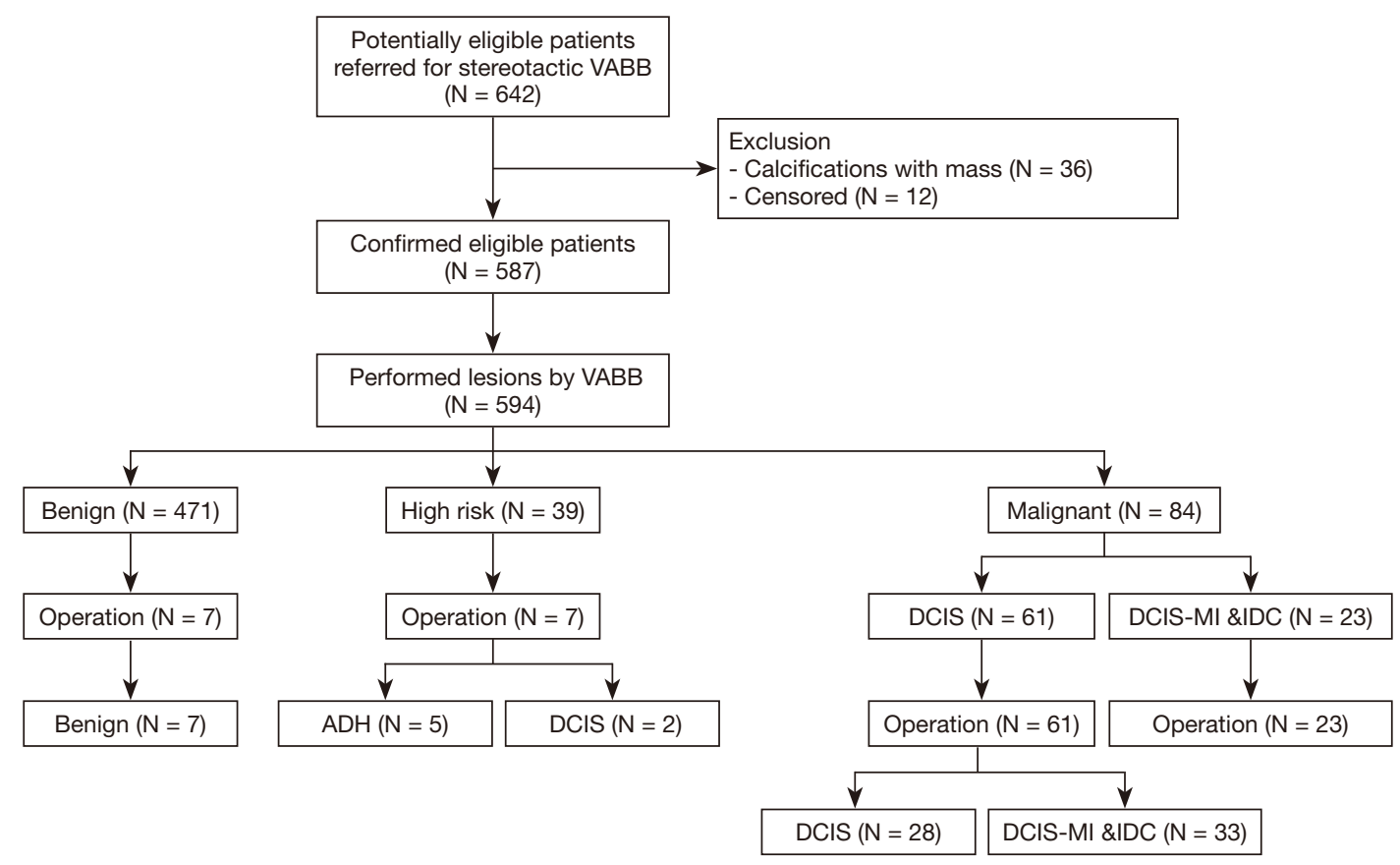

Figure 1 Flowchart of management of study participants.

carcinoma (IDC).

The primary aim of this study was to evaluate and compare the diagnostic consistency and accuracy of specimens with or without calcifications biopsied from same sites of sampling on non-palpable mammographically detected calcifications. The secondary purpose was to review the histopathological underestimation rate and false negative rate in terms of the follow up data and the histopathological result of final surgical specimens. Diagnostic accuracy was defined as the number of malignant lesions diagnosed by VABB calculated as a percentage of the overall number of malignant cases. Histopathological underestimation rate was defined as an $\mathrm{ADH}$ or $\mathrm{ALH}$ lesion of the VABB that was upgraded to in situ or invasive carcinoma after open excisional biopsy and a DCIS or LCIS lesion of the VABB that was upgraded to DCIS-MI or invasive carcinoma after the surgical excision (9). The false negative rate, defined as the development of new malignant lesions during the short-term follow-up ( $<12$ months) of patients with $\mathrm{ADH}$ diagnosed by $\mathrm{VABB}$ without residual calcifications conservatively managed (10).

\section{Management of patients after biopsy}

Most patients with benign biopsy results were referred for mammographic surveillance with 6 month-interval in the first year and every 1-2 years thenceforth. A multidisciplinary team meeting discussion was held in cases of discordance between histopathologic and mammographic results (such as BI-RADS 4C lesions with a benign diagnosis). As there is no consensus in the management of the patients with a diagnosis of $\mathrm{ADH}(10)$, in our study, this group of patients with possibility of complete removal of calcifications was proposed to receive conservative management, while surgical excision was mandatory to patients either with residual calcifications of ADH or malignant lesions. The complication complaints were collected during the follow-up period. The study was conducted in accordance with the Declaration of Helsinki (as revised in 2013). The study was approved by FUSCC Ethical Committee (No. 050432-4-1911D) and informed consent was taken from all the patients.

\section{Statistical analysis}

Data were presented as frequencies and percent distributions, as well as rates and ratios. Descriptive statistics, more specifically nonparametric KruskalWallis test was used for statistical evaluation. A $\mathrm{P}$ value of $<0.05$ was considered to be significant. Data analysis 
Table 1 Histopathological results of VABB specimens corresponding to BI-RADS classification

\begin{tabular}{lrrrrrr}
\hline \multirow{2}{*}{$\begin{array}{l}\text { BI-RADS } \\
\text { category }\end{array}$} & \multicolumn{5}{c}{ Histopathological results of VABB specimens } \\
\cline { 2 - 7 } & Benign & ADH & DCIS & DCIS-MI & IDC & Total \\
\hline 0 & 6 & 0 & 1 & 0 & 0 & 7 \\
3 & 99 & 6 & 5 & 0 & 1 & 111 \\
$4 \mathrm{~A}$ & 324 & 22 & 30 & 4 & 7 & 387 \\
$4 \mathrm{~B}$ & 38 & 9 & 10 & 0 & 2 & 59 \\
$4 \mathrm{C}$ & 4 & 1 & 12 & 2 & 5 & 24 \\
5 & 0 & 1 & 3 & 0 & 2 & 6 \\
Total & 471 & 39 & 61 & 6 & 17 & 594 \\
\hline
\end{tabular}

VABB, vacuum-assisted breast biopsy; BI-RADS, Breast Imaging Reporting and Data System; $A D H$, atypical ductal hyperplasia; DCIS, ductal carcinoma in situ; DCIS-MI, ductal carcinoma in situ with microinvasion; IDC, invasive ductal carcinoma.

was performed using the Statistical Package for Social Sciences (version 20.0) software (SPSS Inc., Chicago, IL, USA).

\section{Results}

A total of 594 consecutive stereotactic VABB procedures were performed in 587 patients (mean age 46 years, range, 21-80 years) (Figure 1). The median follow-up was 56 months (range, 13-108 months). Other demographics and clinical characteristics of enrolled patients were detailed in Table S1.

\section{Imaging lesion characteristics}

Of all 594 mammographically detected lesions, there were seven (1.2\%) BI-RADS 0 lesions, 111 (18.7\%) BI-RADS 3 lesions, 470 (79.1\%) BI-RADS 4 lesions and six (1.0\%) BI-RADS 5 lesions. BI-RADS category 4B lesions $(9.9 \%$ in total) were classified in twenty-five cases involving amorphous calcifications, 14 cases involving coarse heterogeneous calcifications, and 20 fine pleomorphic calcifications, respectively. Thirty cases containing fine linear or fine linear branching calcifications were classified as BI-RADS 4C/5 (Table S1). According to the final pathology results, the malignancy rate with respect to BIRADS lexicon of $4 \mathrm{~A}, 4 \mathrm{~B}, 4 \mathrm{C}$, and 5 were $10.6 \%, 20.3 \%$, $79.2 \%$, and $83.3 \%$, respectively (Table 1 ).
Table 2 Histopathological diagnoses of VABB in 594 calcification lesions

\begin{tabular}{|c|c|c|}
\hline Category & Number & Percent (\%) \\
\hline \multicolumn{3}{|l|}{ Benign $(\mathrm{N}=471)$} \\
\hline Ductasia & 329 & 55.4 \\
\hline Fibroadenoma & 68 & 11.4 \\
\hline Usual ductal hyperplasia & 31 & 5.2 \\
\hline Sclerosing adenosis & 12 & 2.0 \\
\hline Papilloma & 9 & 1.5 \\
\hline Apocrine metaplasia & 9 & 1.5 \\
\hline Columnar cell changes & 6 & 1.0 \\
\hline Fibrocystic changes & 5 & 0.9 \\
\hline Mucocele & 2 & 0.3 \\
\hline \multicolumn{3}{|l|}{ High risk $(\mathrm{N}=39)$} \\
\hline Atypical hyperplasia & 39 & 6.6 \\
\hline \multicolumn{3}{|l|}{ Malignant $(\mathrm{N}=84)$} \\
\hline DCIS, low grade & 12 & 2.1 \\
\hline DCIS, intermediate grade & 22 & 3.7 \\
\hline DCIS, high grade & 27 & 4.5 \\
\hline Microinvasive & 6 & 1.0 \\
\hline IDC & 17 & 2.9 \\
\hline
\end{tabular}

VABB, vacuum-assisted breast biopsy; DCIS, ductal carcinoma in situ; IDC, invasive ductal carcinoma; $A D H$, atypical ductal hyperplasia.

\section{Histopathological results of VABB specimens}

Histopathological examination of biopsy specimens revealed benign pathology in 471 cases (79.3\%), high-risk lesions in 39 cases $(6.6 \%)$, and malignant diseases in 84 cases (14.1\%). The 471 benign lesions contained 11 categories of histological diagnosis (Table 2). Seven cases of sclerosing adenosis and papillary lesions were subjected to further surgical excision after hook wire localization. None of these cases was proved to obscure malignancy (Table S2).

Of the 39 high risk lesions, all cases were diagnosed of $\mathrm{ADH}$. Seven of these patients were referred for additional surgical resection because of residual calcification postVABB detected (Table S2, Figure 2). The underestimation rate for high risk lesion in total was $5.1 \%$, as two cases of $\mathrm{ADH}$ was upgraded to DCIS in the final surgical excision (Figure 1).

The 84 malignant lesions included 61 cases $(72.6 \%)$ of 

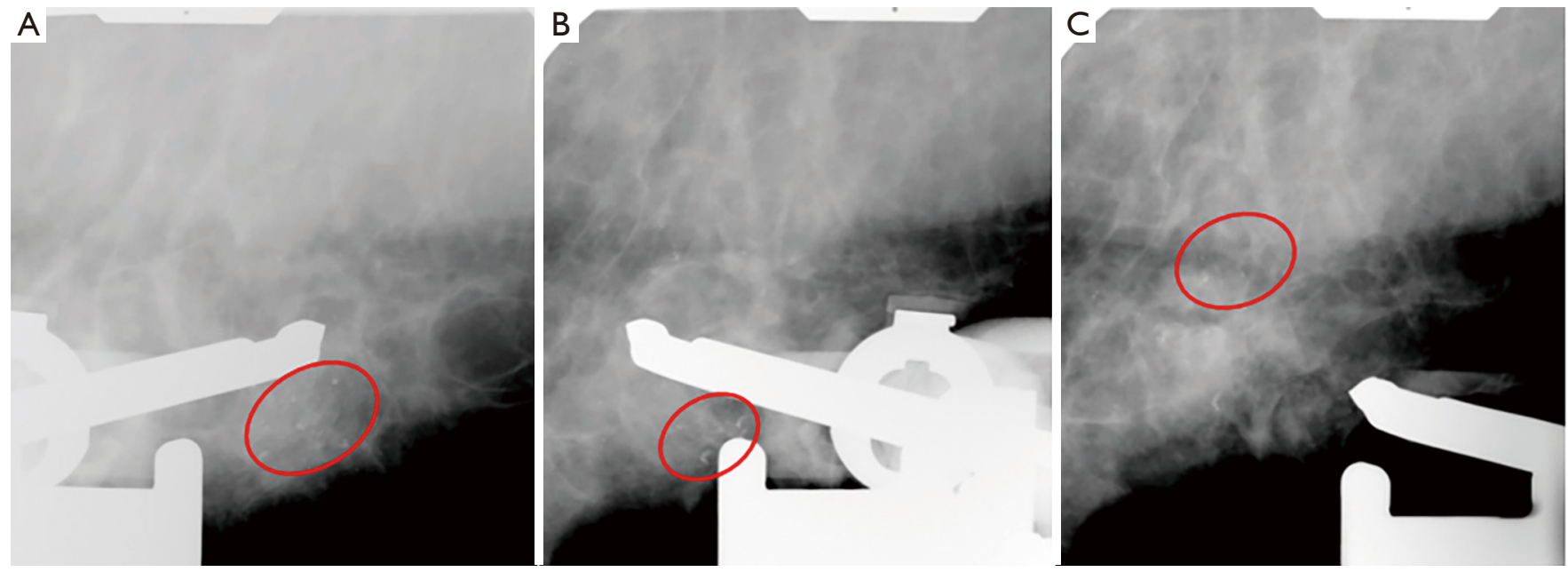

Figure 2 (A-C) Craniocaudal mammogram (A) and magnified MLO image (B) show a cluster of coarse heterogeneous calcifications (red round) in a 55-year-old patient. The lesion was partially excised and histopathology revealed IDC. (C) Post-VABB image showed residual calcifications (red round). The patient was referred immediately to open excisional biopsy. The final pathology examination found an ADH with lobular cancerization. MLO, medio-lateral oblique; IDC, invasive ductal carcinoma; VABB, vacuum-assisted breast biopsy.

Table 3 Diagnostic consistencies of the VABB specimens with or without calcifications

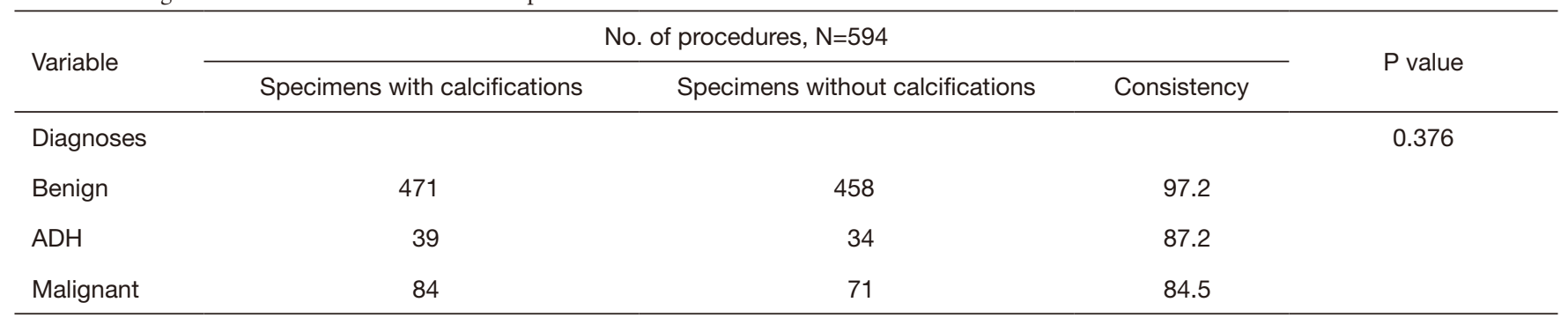

$\mathrm{P}=0.376$ by Nonparametric Kruskal-Wallis test between three histologic groups. $\mathrm{ADH}$, atypical ductal hyperplasia.

DCIS, 6 cases (7.2\%) of DCIS-MI, and 17 cases (20.2\%) of IDC (Table 2). In cases of DCIS diagnosed by VABB, 33 lesions were upgraded to microinvasive carcinoma or IDC after hook wire localization and open surgery. The underestimation rate for in situ carcinoma in total was $54.1 \%$ (Figure 1).

\section{Diagnostic consistencies and accuracy of VABB specimens with or without calcifications}

The mean number of specimens collected per lesion was 14.7 (range, 9-21) for $11 \mathrm{G}$ needle. The specimens that contained calcification lesions and its adjacent tissue were separately submitted to histopathologic assessment. In 563 of 594 lesions $(92.8 \%)$, the histopathologic findings were similar while the histopathologic assessment of 31 specimens without calcifications revealed normal or benign breast tissue. The calcified and noncalcified specimens obtained the same histologic diagnoses in 458 of 471 benign diseases (97.2\%), 34 of $39 \mathrm{ADHs}$ (87.2\%), and 71 of 84 malignant diseases (84.5\%) (Table 3). There was no statistic difference between the benign, atypia and cancer lesions. In 18 lesions (7.2\%), the correct diagnosis was achieved only on specimens with calcifications. Thirteen of 18 lesions (72.2\%) were malignant and five $(27.8 \%)$ were high-risk. The diagnostic discordance indicated that $15.5 \%$ (13 of 84) patients of VABB-diagnosed malignancy would be underestimated by adjacent non-calcified specimens. The accuracy of malignancy diagnosis from the specimens comprising calcifications was $97.7 \%$ (84 of 86 , two underestimated cases for $\mathrm{ADH}$ ) and was only $82.6 \%$ (71 of 86 cancers) for specimens without calcifications, resulting 

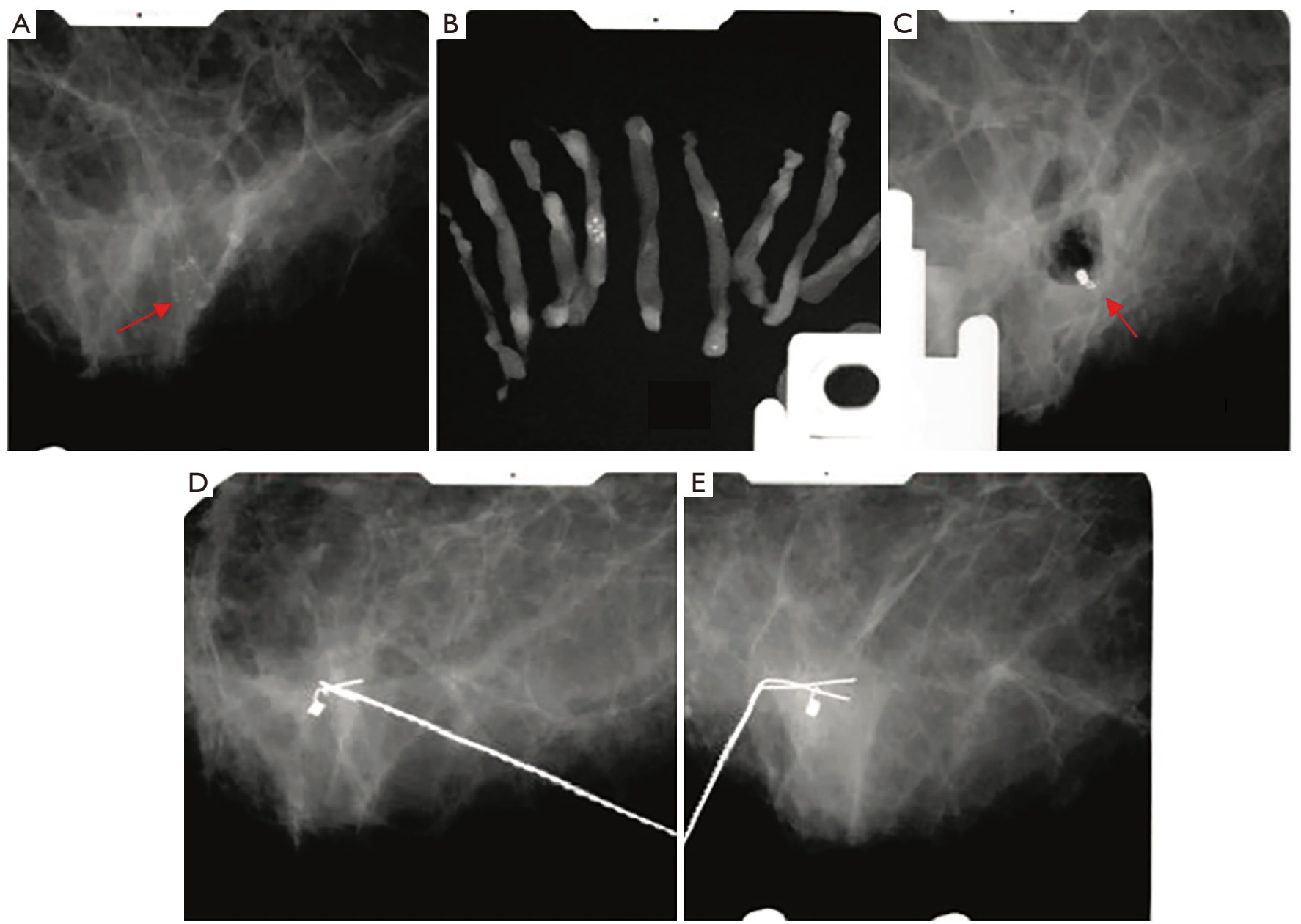

Figure 3 (A-E) Craniocaudal magnification image (A) of a cluster of pleomorphic calcifications (red arrow) in a 52-year-old patient. DCIS was determined at biopsy. (B) Specimens radiography was obtained to ensure the presence of calcification lesions. (C) A post-VABB mammogram was acquired to ensure a radiopaque clip inserted (red arrow). (D-E) The patient underwent the breast conserving treatment after hook wire localization of the clip left at the biopsy site, the final pathological examination revealed no residual lesion. DCIS, ductal carcinoma in situ; VABB, vacuum-assisted breast biopsy.

$15.1 \%$ difference of accuracy. The evaluation of combined noncalcified specimens and calcified specimens did not show advantage over diagnostic accuracy as compared with evaluating calcified specimens alone $(97.7 \%$ versus $97.7 \%$, respectively).

\section{Follow up information}

Follow-up data was available for all 471 benign lesions. Three of these lesions were re-biopsied due to diagnosis escalation of programmed mammography and the biopsy results were all benign. As for patients with $\mathrm{ADH}$ diagnosed of VABB, only two cases developed new suspicious calcifications, in the same breast, 6 and 5 months after the first VABB, respectively. The new lesions with calcifications were openly biopsied, with diagnosis of IDC confirmed. Therefore, a false negative rate of $6.25 \%(2 / 32)$ was noted. All patients with malignant biopsy results underwent surgery (Figure 3). Surveillance was carried out once every 4 to 6 months in the first 3 years after surgery. Three patients experienced local or chest wall recurrence during follow-up period (20,30, and 73 months after the initial surgery, respectively).

\section{Profile of complications}

No severe complications were reported during the biopsy 
procedures. Some mild events were encountered in 14 cases corresponding to $2.4 \%$ of the total VABBs. Among 13 patients, small hematoma was observed thereafter. Only one case experienced syncope because of fasting and nervousness, while the symptoms were relieved after eating and rest.

\section{Discussion}

Above all, our study compared the calcified and noncalcified specimens obtained from the same biopsy site, and the accuracy of calcified specimens was higher than that of noncalcified specimens (97.7\% versus $82.6 \%$ ) in diagnosing malignant calcifications. To the best of our knowledge, this retrospective study provided the largest samples of consecutive stereotactic VABB procedures with separated submission of calcified and noncalcified specimens. Our results were consistent with those of previous studies. Margolin et al. (11) revealed a higher probability of cancer diagnosis from core specimens with calcifications than those without ( $84 \%$ versus $71 \%$, respectively), and the diagnosis of cancer was more likely to be missed in core specimens without microcalcifications (11\% versus $1 \%)$. Cheung et al. (12) also reported a high prevalence of diagnostic discordance between the calcified and noncalcified specimens ( $41.33 \%$ in malignant lesions), which indicated the higher value of calcified specimens in diagnosing atypia and malignant calcifications. Therefore, we thought that noncalcified specimens did not provide additional diagnostic value. The separate submission of calcified and noncalcified specimens might facilitate more precise interpretation for pathologists among the large number of specimens.

Herein, we reported a higher number of specimens with nearly 15 per lesion in comparison to the literature (13). This result might be accredited to the fact that domestic patients are more inclined to have more tissue removed. Several studies have found the diagnostic accuracy of stereotactic VABB in relation to the number of specimens. For stereotactic 11-gauge VABB, the reported sensitivity and specificity in the literature ranges from $85 \%$ to $100 \%$ and $98-100 \%$, respectively (14-19). According to EUSOBI consensus guidelines a minimum of twelve 11-gauge cores should be obtained (2).

In currently available VABB systems, needle size varies from 7 gauge to 14 gauge. In this investigation, 11-gauge $(11 \mathrm{G})$ probe was introduced into our clinical practice, which has yielded a satisfactory performance in terms of feasibility, safety, calcification identification, and accuracy.
This is confirmed by recently published studies comparing underestimation in $11 \mathrm{G}$ - and $8 \mathrm{G}-\mathrm{VABB}$; these studies found no difference between the two needle groups $(20,21)$.

Subdivision of breast calcifications by morphology is practical in predicting the likelihood of malignancy. It is worth noting that, in our study, the likelihood of malignancy as a function of BI-RADS descriptors of calcification morphology was $20.3 \%, 79.2 \%, 83.3 \%$ for 'amorphous', 'coarse heterogenous', and 'fine pleomorphic' respectively, which was consistent with the results of several single-institution consecutive-case series (22).

A histopathological upgrade has an important impact in surgical management pattern. In our study, among 39 highrisk $(\mathrm{ADH})$ cases, only two escalated to DCIS after surgery, accounting for an underestimation rate of $5.1 \%$. This result was comparable with those reported in the literature (9,23-25). Of 61 cases of DCIS diagnosed by VABB, 23 were upgraded to DCIS-MI or invasive carcinoma after open excision. The underestimation rate was $54.1 \%$, which is remarkably higher than that reported in other series due to the broader inclusion of microinvasive lesion. This is important because sentinel lymph node biopsy is the routine practice for patients with invasive component other than in situ disease.

There lies controversy over whether all patients diagnosed with $\mathrm{ADH}$ by VABB should undergo immediate wide resection (26,27). Schiaffino et al. (10) justify the conservative management in a highly selected group of patients with a single group of calcifications, without residual post-procedure and without the presence of multiple foci of hyperplasia or high proportion of hyperplasia at histopathological evaluation. Moreover, Esen et al. (25) investigated that patients with no residual calcifications could be conservatively managed with fixed mammogram follow-up instead of further surgical resection. During the next 2-3 years of follow-up, no interval changes were detected in this subset of patients. These results are in line with data from our study. Of 39 patients with $\mathrm{ADH}$ diagnosed by VABB, only 7 cases with residual calcifications were recommended to surgical resection, two of which were upgraded to DCIS in the final histopathological analysis. The remaining thirty-two patients, with totally removed calcifications, were arranged for close follow-up without surgical resection. Among them, only 2 patients $(6.25 \%)$ developed new suspicious calcifications in the same breast within one year, interpreted both as IDC at surgical excision. These results might justify the conservative approach, in a highly selected group of patients, being the 
false negative rate approximately equal to $6 \%$, regarded as the "probably benign" category in the literature.

There are some limitations in this study. Firstly, this is a single-institution retrospective study, so bias derived from the centre could not be excluded. Secondly, not all patients with atypical lesions underwent subsequent surgery. Although open excision was recommended for all atypical cases irrespective of the size of the lesion, certain physicians would rather choose follow-up than complete excision, probably in accordance with patients' demand. Thirdly, the follow-up length is limited for high-risk lesions without further intervention, in which we might encounter malignancy during longer surveillance.

In conclusion, stereotactic VABB is an accurate and safe technique for the investigation of non-palpable mammographically suspicious calcifications. The high prevalence of diagnostic discordance between the specimens with and without calcifications revealed a higher value of calcified specimens in diagnosing high-risk and malignant calcifications.

\section{Acknowledgments}

We are grateful to the colleagues in department of Pathology and Radiology for providing excellent data resources.

Funding: None.

\section{Footnote}

Reporting Checklist: The authors have completed the STROBE reporting checklist. Available at http://dx. doi. org/10.21037/gs-20-456

Data Sharing Statement: Available at http://dx. doi. org/10.21037/gs-20-456

Peer Review File: Available at http://dx. doi. org/10.21037/ gs $-20-456$

Conflicts of Interest: All authors have completed the ICMJE uniform disclosure form (Available at http://dx. doi. org/10. 21037/gs-20-456). The authors have no conflicts of interest to declare.

Ethical Statement: The authors are accountable for all aspects of the work in ensuring that questions related to the accuracy or integrity of any part of the work are appropriately investigated and resolved. The study was conducted in accordance with the Declaration of Helsinki (as revised in 2013). The study was approved by FUSCC Ethical Committee (No. 050432-4-1911D). Written informed consent was obtained from the patient for publication of this study and any accompanying images. A copy of the written consent is available for review by the Editor-in-Chief of this journal.

Open Access Statement: This is an Open Access article distributed in accordance with the Creative Commons Attribution-NonCommercial-NoDerivs 4.0 International License (CC BY-NC-ND 4.0), which permits the noncommercial replication and distribution of the article with the strict proviso that no changes or edits are made and the original work is properly cited (including links to both the formal publication through the relevant DOI and the license). See: https://creativecommons.org/licenses/by-nc-nd/4.0/.

\section{References}

1. Meyer JE, Smith DN, Lester SC, et al. Large-core needle biopsy of nonpalpable breast lesions. Jama 1999;281:1638-41.

2. Bick U, Trimboli RM, Athanasiou A, et al. Image-guided breast biopsy and localisation: recommendations for information to women and referring physicians by the European Society of Breast Imaging. Insights Imaging 2020;11:12.

3. Fahrbach K, Sledge I, Cella C, et al. A comparison of the accuracy of two minimally invasive breast biopsy methods: a systematic literature review and meta-analysis. Arch Gynecol Obstet 2006;274:63-73.

4. Yu YH, Liang C, Yuan XZ. Diagnostic value of vacuumassisted breast biopsy for breast carcinoma: a metaanalysis and systematic review. Breast Cancer Res Treat 2010;120:469-79.

5. Houssami N, Ciatto S, Ellis I, et al. Underestimation of malignancy of breast core-needle biopsy: concepts and precise overall and category-specific estimates. Cancer 2007;109:487-95.

6. Verkooijen HM. Diagnostic accuracy of stereotactic largecore needle biopsy for nonpalpable breast disease: results of a multicenter prospective study with $95 \%$ surgical confirmation. Int J Cancer 2002;99:853-9.

7. Mercado CL. BI-RADS update. Radiol Clin North Am 2014;52:481-7.

8. Park HL, Hong J. Vacuum-assisted breast biopsy for breast 
cancer. Gland Surg 2014;3:120-7.

9. Safioleas PM, Koulocheri D, Michalopoulos N, et al. The value of stereotactic vacuum assisted breast biopsy in the investigation of microcalcifications. A six-year experience with 853 patients. J buon 2017;22:340-6.

10. Schiaffino S, Massone E, Gristina L, et al. Vacuum assisted breast biopsy (VAB) excision of subcentimeter microcalcifications as an alternative to open biopsy for atypical ductal hyperplasia. Br J Radiol 2018;91:20180003.

11. Margolin FR, Kaufman L, Jacobs RP, et al. Stereotactic core breast biopsy of malignant calcifications: diagnostic yield of cores with and cores without calcifications on specimen radiographs. Radiology 2004;233:251-4.

12. Cheung YC, Juan YH, Ueng SH, et al. Assessment of Breast Specimens With or Without Calcifications in Diagnosing Malignant and Atypia for Mammographic Breast Microcalcifications Without Mass: A STARDCompliant Diagnostic Accuracy Article. Medicine (Baltimore) 2015;94:e1832.

13. den Dekker BM, van Diest PJ, de Waard SN, et al. Stereotactic 9-gauge vacuum-assisted breast biopsy, how many specimens are needed? Eur J Radiol 2019;120:108665.

14. Pfarl G, Helbich TH, Riedl CC, et al. Stereotactic 11-gauge vacuum-assisted breast biopsy: a validation study. AJR Am J Roentgenol 2002;179:1503-7.

15. Apesteguía L, Mellado M, Sáenz J, et al. Vacuum-assisted breast biopsy on digital stereotaxic table of nonpalpable lesions non-recognisable by ultrasonography. Eur Radiol 2002;12:638-45.

16. Kettritz U, Rotter K, Schreer I, et al. Stereotactic vacuumassisted breast biopsy in 2874 patients: a multicenter study. Cancer 2004;100:245-51.

17. Killebrew LK, Oneson RH. Comparison of the diagnostic accuracy of a vacuum-assisted percutaneous intact specimen sampling device to a vacuum-assisted core needle sampling device for breast biopsy: initial experience. Breast
J 2006;12:302-8.

18. Lomoschitz FM, Helbich TH, Rudas M, et al. Stereotactic 11-gauge vacuum-assisted breast biopsy: influence of number of specimens on diagnostic accuracy. Radiology 2004;232:897-903.

19. Weber WP, Zanetti R, Langer I, et al. Mammotome: less invasive than ABBI with similar accuracy for early breast cancer detection. World J Surg 2005;29:495-9.

20. Venkataraman S, Dialani V, Gilmore HL, et al. Stereotactic core biopsy: Comparison of 11 gauge with 8 gauge vacuum assisted breast biopsy. Eur J Radiol 2012;81:2613-9.

21. Ruggirello I, Nori J, Desideri I, et al. Stereotactic vacuumassisted breast biopsy: Comparison between 11- and 8-gauge needles. Eur J Surg Oncol 2017;43:2257-60.

22. Ling H, Liu ZB, Xu LH, et al. Malignant calcification is an important unfavorable prognostic factor in primary invasive breast cancer. Asia Pac J Clin Oncol 2013;9:139-45.

23. Pan S, Liu W, Jin K, et al. Ultrasound-guided vacuumassisted breast biopsy using Mammotome biopsy system for detection of breast cancer: results from two high volume hospitals. Int J Clin Exp Med 2014;7:239-46.

24. Imschweiler T, Haueisen H, Kampmann G, et al. MRIguided vacuum-assisted breast biopsy: comparison with stereotactically guided and ultrasound-guided techniques. Eur Radiol 2014;24:128-35.

25. Esen G, Tutar B, Uras C, et al. Vacuum-assisted stereotactic breast biopsy in the diagnosis and management of suspicious microcalcifications. Diagn Interv Radiol 2016;22:326-33.

26. Renshaw AA, Gould EW. Long term clinical follow-up of atypical ductal hyperplasia and lobular carcinoma in situ in breast core needle biopsies. Pathology 2016;48:25-9.

27. Latronico A, Nicosia L, Faggian A, et al. Atypical ductal hyperplasia: Our experience in the management and long term clinical follow-up in 71 patients. Breast 2018;37:1-5.
Cite this article as: Li S, Qu F, Yang Y, Wang L, Shen J, Shao Z. Value of stereotactic 11-gauge vacuum-assisted breast biopsy in non-palpable suspicious calcifications: an eight-year single institution experience with 587 patients. Gland Surg 2020;9(5):1258-1266. doi: 10.21037/gs-20-456 


\section{Supplementary}

Table S1 Patients' demographics and radiological data

\begin{tabular}{|c|c|}
\hline Variable & $\mathrm{N}(\%)$ \\
\hline \multicolumn{2}{|l|}{ Demographic characteristics ( $\mathrm{N}=587$ ) } \\
\hline Age at diagnosis, median [range] & 46 [21-80] \\
\hline \multicolumn{2}{|l|}{ Prior history of breast cancer } \\
\hline Yes & $33(5.6)$ \\
\hline No & $554(94.4)$ \\
\hline \multicolumn{2}{|l|}{ Side of breast procedure } \\
\hline Left & $305(52.0)$ \\
\hline Right & $282(48.0)$ \\
\hline \multicolumn{2}{|l|}{ Mammographic features } \\
\hline \multicolumn{2}{|l|}{ BI-RADS lexicon $(\mathrm{N}=594)$} \\
\hline 0 & $7(1.2)$ \\
\hline 3 & $111(18.7)$ \\
\hline $4 \mathrm{~A}$ & $387(65.2)$ \\
\hline 4B & $59(9.9)$ \\
\hline $4 \mathrm{C}$ & $24(4.0)$ \\
\hline 5 & $6(1.0)$ \\
\hline \multicolumn{2}{|l|}{ Calcification morphology $(\mathrm{N}=89)$} \\
\hline Amorphous & $25(28.1)$ \\
\hline Coarse heterogeneous & $14(15.7)$ \\
\hline Fine pleomorphic & $20(22.5)$ \\
\hline Fine linear/fine linear branching & $30(33.7)$ \\
\hline
\end{tabular}

BI-RADS, Breast Imaging Reporting and Data System.
Table S2 Clinicopathological characteristics of 14 benign or highrisk lesions referred for open excisional biopsy

\begin{tabular}{|c|c|}
\hline Variable & $\mathrm{N}(\%)$ \\
\hline \multicolumn{2}{|l|}{ Demographic characteristics $(\mathrm{N}=14)$} \\
\hline Age at diagnosis, median [range] & 49 [32-61] \\
\hline \multicolumn{2}{|l|}{ Prior history of breast cancer } \\
\hline Yes & $2(14.3)$ \\
\hline No & $12(85.7)$ \\
\hline \multicolumn{2}{|l|}{ Mammographic features } \\
\hline \multicolumn{2}{|l|}{ BI-RADS lexicon } \\
\hline $4 \mathrm{~A}$ & $3(21.4)$ \\
\hline 4B & $4(28.6)$ \\
\hline $4 \mathrm{C}$ & $6(42.9)$ \\
\hline 5 & $1(7.1)$ \\
\hline \multicolumn{2}{|l|}{ Final surgical histopathology } \\
\hline $\mathrm{ADH}$ & $5(35.7)$ \\
\hline Sclerosing adenosis & $4(28.6)$ \\
\hline Papilloma & $3(21.4)$ \\
\hline DCIS & $2(14.3)$ \\
\hline
\end{tabular}

BI-RADS, Breast Imaging Reporting and Data System; ADH, atypical ductal hyperplasia; DCIS, ductal carcinoma in situ. 